\title{
A framework for Marketing Libraries in the Post- Liberalized Information and Communications Technology Era
}

\author{
Author: Garimella Bhaskar Narasimha Rao \\ Associate Professor, MBA Department \\ DIET, Anakapalle, Visakhapatnam, India
}

\begin{abstract}
The role of library is professional and is fast customizing to altering technological platforms. Our subscriber's perceptions of the nature of our libraries are also altering like never before - particularly in Universities. In this dynamic environment the efficient presentation of the library is an essential survival tool. This holds true whether a library is contributing effectively to an institution's overall management effort or, sensitively and subtly, promoting rational attitudes in the minds of its local constituency. Citations, references and annotations referred here are intended to provide background, ideas, techniques and inspiration for the novice as well as the experienced personnel. We hope you will find this paper as interesting and useful as we trust it would be, and that libraries may gain in useful collaborations and reputation from the application of information provided by resources identified here. Result oriented marketing is not on its own - some kind of substitute for a well-run service provider or service the demands of its user population, but in the 21st century even the best-run centers of learning or information service will only prosper if effort and talent are devoted to growth orientation. Almost all of us can render to this effort, and this paper can help coax the roots of marketing talent into a complete, harvestable and fragrant flower.
\end{abstract}

Keywords-Digital Libraries, University Learining, Adaptability

\section{INTRODUCTION}

This paper is intended to serve as a source of inspiration, innovation and resources for librarians who are setting out to administer and roll-out projects in a fast-moving, everchanging and potentially dynamic arena. A new perspective, addressing the marketing of library information, products and services has been moving up in the chronological list of challenges to be addressed on a priority. The whole area of marketing and "selling the library" is a concept which many information professionals still feel nests uneasily with our core professional values of service and empathy. Yet, the library and information science (LIS) professionals can no longer look at reputed publications which emphasize this introduction and think it has no bearing on our own.

\section{BACKGROUND \& RELATED WORK}

Ghosh Maitrayee (March 2009). This research presented the developments in ETD repositories and performed a preliminary study to explore the possibilities for creating a national repository for the submission, identification, use and long-term care of research theses in an open access environment. The authors look at the current state of deployment of ETD repositories in the academia and discuss the subject coverage, number of items, access policy, search/browse option, and value added services. This study posed questions about policies and strategies that, research funding, national higher education and policy-making bodies, as well as individual institutional communities within the higher education might want to consider. This research paper was titled "A case study of nine ETD digital libraries and formulation of policies for a national service and published in the International Information \& Library Review, Volume 41, Issue 1.

Bárbara L. Moreira, Gonçalves A. Marcos, Laender Alberto H.F, Fox Edward A. (April 2009).

This research work which was published under the title "Automatic evaluation of digital libraries with 5SQual and published in the Journal of Informetrics, Volume 3, Issue 2 was targeted to alter the situation with the creation of 5SQual, a tool which provides ways to perform systemized and configurable evaluations of some of the most important Digital Library components, encompassing metadata, digital objects and services. In total, the main contributions of this work include: (i) the applicability of the application in several usage scenarios; (ii) the implementation and design of 5SQual; and (iii) the evaluation (including specialists usability) of its graphical interface specially designed to guide the configuration of 5SQual evaluations. The results present the analysis of interviews conducted with administrators of real Digital Libraries regarding their opinions and expectations about 5SQual.

Frias-Martinez Enrique, Chen Sherry Y., Liu Xiaohui (February 2009).

This research asserts that, personalization can be accounted for by adaptability and adaptivity, which have different pros and cons. This study investigated how digital library (DL) users react to these two techniques. The research was titled "Evaluation of a personalized digital library based on cognitive styles": Adaptivity vs. Adaptability was published in 
the International Journal of Information Management, Volume 29, Issue 1 and the authors developed a personalized DL to address the needs of different cognitive styles based on the findings of their previous work [Frias-Martinez, E., Chen, S. Y., \& Liu, X. (2008) Investigation of behavior and perception of digital library users: A cognitive style perspective: International Journal of Information Management. The personalized DL included two versions: adaptable version and adaptive version. Results reflected that users not only performed better in the adaptive version, but also perceived more positively to the adaptive version. The primary assertion and conclusion was that cognitive styles have great effects on users' responses to adaptivity and adaptability. Results provided were aimed to render guidance for designers to select suitable techniques to structure personalized DLs.

Porcel C., Moreno J.M., Herrera-Viedma E. (December 2009)

The main theme was that the internet is one of the most important information media and it is influencing in the development of other media, as for example, newspapers, journals, books, and libraries. In this paper, The authors analyzed the logical extensions of traditional libraries in the Information Society. and present a model of a fuzzy linguistic recommender system to help the University Digital Libraries users to access for their research resources. This system recommended researchers specialized in complementary resources to discover collaboration possibilities to form multidisciplinar groups. The research was titled "a multi-disciplinar recommender system to advice research resources in University Digital Libraries" and published in the Journal of Expert Systems with Applications, Volume 36, Issue 10.

\section{III.DOMAINS That REQUIRE ANALYSIS - A PERSPECTIVE OF CHALlenges}

The Digital Library of a University requires a unified portal that would enable comprehensive searching and access rights to all library electronic resources from a single entry point. Disparate purchasing, management, and work related policies have previously led to a need to lower user confusion. The library with a sophisticated system to manage the different licensing agreements and access rights matrices of various units.

The Library of a University primarily serves the purpose of providing access to its complete collection. The implemented technology platform assists and enables the search and the mentioned access to electronic and digital publications. Based on centuries of educational tradition (like the University of Taxila, India), a large University student body imbibes a resident city with a youthful and lively character. Numerous graduate, postgraduate students and teaching staff make use of a University's huge library information system--based on the network of various branches and allied libraries for the automation and access to print collections. Once the basic project of collating and establishing the printed books collection gets over, a librarian needs to turn his focus towards the management of the libraries electronic resources.

When electronic resources first became available, many librarians had to address the challenges of uniform purchasing, management, and the creation of usage policies for academic libraries that were served. As a result, each university faculty was required to provide a list of publications and e-resources relevant to its area of study that needed purchasing. These materials were often restricted to the users associated with that specific faculty, and were only made available to them via a network or any specific other search systems developed by that department. A few of these systems assisted virtual private network access to the library resources while others required users to access the resources from within the library.

Researchers wishing to browse through any library resources could be faced with different entry points and interfaces rather than a consolidated listing of all library holdings. This left users frustrated and led to under-use of many valuable high-cost resources. This quickly established that a unified library portal, via which users could perform a federated searching across all of the resources, was deemed essential. Drawing up a list of requirements for choosing a library solution that would help us to meet the goals of the digital library project, would be; on one hand, libraries need systems sophisticated enough to accommodate the different copyright agreements and access rights entitlements of various converging units. On the other hand, the system has to provide a single point of entry through which all users, regardless of access authority, who access the library's complete collection displayed via a list and a catalog of resources.

The University library exists to benefit a diverse set of people. The associates mentioned here are the societies, undergrads to post grads, teaching and non-teaching fraternity. These groups may be further be segmented by roles, characteristics, or interests, members for whom, English is a second language for the purposes of specific marketing activities. As an institution which is established from student fees and non-governmental grants and as a repository for government information, librarians also have an added responsibility to serve the local society. Again, within the local society, there are multiple subsets that could serve our local society. Again within the local society there are multiple subsets that could be of particular interest to librarians as they market services and resources. It is here that, technology makes an impact and assists selective promotion on a global platform. Research Scholars interested in a library's unique collections may also be audience for a library's long-term marketing plan. In this context it is apt to quote that, the university libraries have been presented both in the library profession and in the higher education segment as a showcase for its architecture and information technologies. 


\section{IV.LibRARIES IN THE POST LIBERALIZED ERA - A FEW THOUGHT STARTERS}

Libraries are deemed to posses reliable and convenient information selected to meet a users research needs and learning styles. Also libraries have unique and valuable regional materials on issues of national interest such as rural development, and crops management in a dry environment, mobile computing, nuclear power generation architecture and health development to name a few.

Libraries assist and cater to the development of literacy skills crucial for extended learning and professional success, namely the ability to ascertain and access, evaluate and effectively utilize information in all of its various formats. Helpful library staff are to be made available and accessible within the facility and remotely, to collaborate with patrons in a one on one set-up or in group settings, to provide subject specific or general assistance. Association with the library in the form, of an ID (physical or electronic or biometric) can help in authenticating users. Libraries cater to their users with sound-proof venues, inviting with comfortable spaces to read, research, study, relax, explore, learn, assimilate with convenient access to print (Paid and free) and electronic information with the latest hardware and software that today's users need and expect.

For librarians engaged in strategic planning encompassing information and communications technology (ICT), guidance from confirmed sources can result valuably. There can unfortunately be a great deal of challenges associated with much written components regarding the strategic use to which modern ICT can be utilized in organizations throughout the Globe these days. Re-sounding yet vague terms such as 'Information Technology Enabled Services' and 'Business Process Outsourcing' frequent the popular media channels on the subject. The Journal of Strategic Information Systems takes a more critical outlook. In publishing papers authored from scholarly study and utilizing research from all nooks and corners of the globe, modern libraries provide a truly impressive array of information on how centers of learning can utilize ICT strategically to avoid associated pitfalls.

To identify the importance of the marketing plan for the overall success of a library and emphasize the need to include a marketing plan within a library's strategic plan. Further we need to identify components to include in a marketing plan and hence provide a procedure book to generate such a plan. Quoting many eminent librarians, components essential to a marketing plan encompass determining what to promote, defining a target audience, choosing types of outreach, and evaluation.

Publicity Guidelines: Many companies use public relations to assist other promotional efforts. It is a very potent tool that could always be part of a library's marketing mix. The specified 5-step guideline can assist a librarian's public relations efforts and can closely coordinate with promotional campaigns so as to achieve a greater impact.
1. Deliberate on and choose the right media.

2. Do have a good grounding on the media type.

3. Timing \& Packaging your news is pivotal

4. Ensure you follow-up in person.

5. Establish a strong relationship and cement the same.

For a library to market itself in the Post Liberalized world, it needs to have a focus to achieve some or all of the goals identified as below.

\section{Goals of a Library - Not limited to}

1. Sponsorship of events, aimed primarily at students and teachers to promote the library's resources and services and to address library anxiety at the start of each session as a follow-up to participation in orientation activities.

a. To solicit for volunteers twice a year to form event planning teams lead by a member from the corporate communications committee.

b. Choose a key theme for each such event.

c. Establish monetary budgets for the event and associate promotional materials.

2. Collate a rule book in conjunction with allied departmental libraries, and an informational guide for students and users as an annual publication for donors and community leaders and associates of the library highlighting the accomplishments, thanking donors and gift contributors.

a. Seek general suggestions / comments from

i. Within departments of the library.

ii. Specific groups (if any) in the libraries.

iii. External participants to the Library.

b. Define and establish editorial responsibilities.

c. Identify potential contributors within the Institution

3. To collaborate on strategic alliances with on and off campus groups to promote the library via pre-existing vehicles and to provide more responsive services to these campus groups and their constituents.

a. Identify key opportunities for expansion

b. Seek for input and help from the libraries' staff

c. Seek for opportunities to publish in the newsletter of student services offices and other academic departments

4. To advertise campus-wide and in the community. Efficient advertising will be essential to the library's success in attracting and retaining users. Potential users need to be made aware of the high quality services and products available to them-mostly without a monetary charge. 
a. Utilize relevant payments of library campaigning for campus and community advertizing.

b. Link into promotions and events sponsored by Library associations when applicable.

c. Utilize media: Issue press releases and public announcements for promotional events and to add to the depiction of libraries and allied resources.

5. Allocate resources to the annual reception for faculty authors

a. Define authorship to include the creation of books and performing accomplishments.

b. In cooperation with the Rector's office and library administration, establish date and place and budget of reception.

c. Seek for participant lists and other campus publications noting faculty work.

\section{V.FUTURE TRENDS}

Library services are bound to increase in the ICT segment viz., electronic databases and electronic journals. The World Wide Web will continue to act as a change agent in the usage of library print and subscription to its database resources. The trend towards electronic development and maintenance of library materials would make library resources accessible readily from home or other off campus systems. Promotional material and activities need to create a desire or need to visit the library in person for instruction and educational support services. One of the primary challenges is to market a library's resource to online users through the central command office of the host university. Another notable challenge is to market library services to patrons on and off campus.

\section{VI.CONCLUSION}

To be effective in achieving the library's aims, any university needs to understand the overall environment in which it functions. For an established University, this means knowing its customers and competitors; for modern libraries, it means mainly (but not limited) understanding its users and their potential demands. A thorough environmental scan will hand-hold a library in developing and marketing its services as deemed necessary in a measurable environment, and can be crucial to its health and efficiency. The references quoted in this paper give a bit of theory and practical advice regarding how to discover the demographics of a library's universe; the process of ascertaining the needs and preferences of its actual and potential users; and the methodology of analyzing all available / possible factors, external and internal, to cater to the library's strategic planning process. All types of institutions (academic and non-academic) providing information need to pay attention to the process of serving customers and manage with media and public relations. In order to provide good customer service, a library must primarily make sure that its customers know of the available services and rendering schedule (time-frames). Whether an information organization is an academic or professional library, any or all publishing houses or a patent office, needs to get word out about services available and take care of customers and prioritize their primary needs. By seeking to understand how diverse information is stored in today's ICT world, a library needs to structure its rendered services and manage public relations, sharing of best practices may be outlined, identified and advantages gained for a better tomorrow.

Interactivity is a mandated aspect of student-centered course design framework, especially in the internet era. Students more often than not, require learning institutions to generate graduates who are problem solvers and creative thinkers; personnel who are literate enough to function well in a knowledge-centric economy. To achieve this educational goal, ICT needs to reform traditional methods of instruction, shifting from a more passive method of teaching to more interactive methodologies.

However, the concern of how to evaluate the coveted goal of interactivity in a class is not often fully addressed, as asserted by this study. Based on four years of ICT enabled design and delivery, this paper has proposed multiple factors and criteria to that can be considered in determining how interactivity can be improved and evaluated. Fundamentally, teachers ought to consider their teaching environment as one of a conversation between an instructor and learner in what this research terms "Conversational Learning Society". Imperative components in this environment include Learners, instructor(s), course materials, and links to remote experts and resources enabled by ICT. All these components are fastened intact by instructional interactivity. Three types of instructional interactivity ought to be recognized. These are learner-learner, instructor-learner and learner-resource interactivity.

To evaluate interactivity one could mull-over both quantitative and qualitative criteria. On the qualitative aspects a teacher needs to pay attention to issues such as initiative, critical thinking and academic rigor coupled with the factor "how far the students seem to be showing signs of these". On the quantitative aspects it may be helpful to consider various log-on statistics on the course homepage and other related statistics about student appraisal of the coursework.

The criteria of how to successfully evaluate the magnitude to which a course design facilitates interaction is bound to remain for a long time - a contentious one. Regardless of the case with regard to the issue of evaluation, this study asserts and concludes that interactivity on the web enhances even tutorial sessions and traditional classroom. ICT enabled Interactive web-based design can allow teachers to achieve a better functional management of their courses, leading to a more effectual scholarship of learning and teaching. 


\section{REFERENCES}

[1] Altman, M., Andreev, L., Diggory, M., Krot, M., King, G., Kiskis, D., Kolster, E., Sone, A.,\&Verba, S. (2001). An introduction to theVirtual Data Center project and software. In, Proceedings of the first ACM+IEEE Joint Conference on Digital Libraries. New York: ACM.

[2] Andreasen, A. R., \& Kotler, P. (2002). Strategic marketing for nonprofit organizations (6th ed.) Upper Saddle River, NJ: Prentice Hall Press.

[3] Barnard, R. (1995) Interactive Learning: A key to successful distance delivery, The American Journal of Multimedia, 12, 45 - 47.

[4] Berry, L. L. (1995). On great service: A framework for action. New York: Free Press.

[5] Blurton, C. (1999) New directions of ICT-use in education, UNESCO's World Communication and Information Report 1999. URL: http://www.unesco.org/education/educprog/lwf/d1/edict.pdf

[6] Boaden, S. (2005). Building public library community connections through cultural planning. Australasian Public Libraries and Information Services, 18 (1), 29-36.

[7] Bodomo, A. (2000) Interactivity in Web-based (Distance Education) Courses, CD-ROM, Proceedings of the Ghana Computer Literacy \& Distance Education (GhaCLAD) Conference, 26th - 29th July, 2000, Accra, Ghana.

[8] Bodomo, A. (2001) Interactivity in Web-based courses, Paper for the WebCT Asia Pacific Conference, 9th-11th April 2001, Adelaide, Australia. Brogan, Pat. (1999) 'Using the web for interactive teaching and learning: An imperative for the new millennium', A white paper for the Macromedia's Interactive Learning Division

[9] Bruner, J. (1966) Toward a Theory of Instruction, Cambridge, MA: Harvard University Press.

[10] Bruner, J. (1983) Child's Talk: Learning to Use Language, New York: Norton.

[11] Bruner, J. (1986) Actual Minds, Possible Worlds, Cambridge, Harvard University Press.

[12] Bruner, J. (1990) Acts of Meaning, Cambridge, MA: Harvard University Press.

[13] Ceci, S., \& Walker, E. (1983). Private archives and public needs. American Psychologist, 38, 414-423.

[14] Cowan, R. S. (1997). A social history of American technology. New York: Oxford University Press.

[15] Davis-Kahl, S. (2004). Creating a marketing plan for your academic and research library. Retrieved from Illinois Wesleyan University website

[16] Daniel, J. and C. Marquis. (1983) Independence and interaction: Getting the mix right, Teaching at a Distance, 15, 445-460.

[17] Daniel, R. (1997). A trivial convention for using HTTP in URN resolution [Online] (Internet Engineering Task Force, No. RFC 2169). Retrieved from the World Wide Web: http://www.ietf.org/.

[18] Davis, J. R.,\&Lagoze, C. (2000). NCSTRL: Design and deployment of a globally distributed digital library. JASIS, 51, 273-280.

[19] Feigenbaum, S., \& Levy, D. M. (1993). The market for (ir)reproducible econometrics. Social Epistemology, 7, 215-292.

[20] Freire, Paulo. (1970) The Adult Literacy Process as Cultural Action for Freedom, Harvard Educational Review, 40, 205-212

[21] Griffin, S. M. (1998). NSF/DARPA/NASA digital libraries initiative: A program manager's perspective. D-Lib Magazine [Online serial], 4(7). Retrieved May 1, 2001, from the World Wide Web: http://www.dlib.org/dlib/july98/07griffin.html
[22] Ihaka, R., \& Gentleman, R. (1996). R: A language for data analysis and graphics. Journal of Computational and Graphical Statistics, 5, 299-314.

[23] Jackson, Robert H. (2000) Web-based Learning Resources Library, Available HTTP:http://www.outreach.utk.edu/weblearning /(email:rhjackson@utk.edu)

[24] Kearsley, Greg. (1994-2000) Explorations in Learning \& Instruction: Theory in Practice Database, Available HTTP:http://www.gwu.edu/ tip/ (May 21, 2000).(email:gkearsley@sprynet.com) http://home.sprynet.com/ gkearsley

[25] Kotler, P., Bloom, P. N., \& Hayes, T. (2002). Marketing professional services: Forward-thinking

[26] strategies for boosting your business, your image, and your profits (2nd ed.). Paramus, NJ: Prentice Hall Press.

[27] Laurie, B., Laurie, P., \& Denn, R. (Ed.). (1998). Apache: The definitive guide. Sebastapol, CA: O'Reilly and Associates. Altman et al. / VIRTUAL DATA CENTER 469

[28] Lee, D. (2005). Can you hear me now? Using focus groups to enhance marketing research. Library Administration \& Management, 19 (2), 100101.

[29] Lessig, L. (1999). Code, and other laws of cyberspace. New York: Basic Books.

[30] Markwood, R. and S. Johnstone. (1994) New Pathways to a degree: Technology opens the college, Western Cooperative for Educational Telecommunications, Western Interstate Commission for Higher Education, Boulder, CO.

[31] McCullough, B. D.,\&Vinod, H. D. (1999). The numerical reliability of econometric software. Journal of Economic Literature, 37, 633-665.

[32] McKenna, R. (2002). Total access: Giving customers what they want in an anytime, anywhere world. Boston: Harvard Business School Press.

[33] Moore, M. (1991) Editorial: distance education theory, The American Journal of Distance Education, 5(3), 1- 6.

[34] Moore, M. (1992) Three types of interaction, The American Journal of Distance Ed, 3 (2), 1-6.

[35] Moore, M. (1993) Theory of transactional distance, in Desmond Keegan (Eds.) Theoretical Principles of Distance Education, London \& New York: Routledge.

[36] Parker, Angie. (1999) Interaction in Distance Education: The critical conversation, Education Technology Review, 13.

[37] Pask, G. (1975) Conversation, Cognition, and Learning, New York: Elsevier.

[38] Piaget, J. (1973) To Understand is to Invent, New York: Grossman.

[39] Plosker, G. (2005). The information strategist: Revisiting library funding: What really works? Online, 29 (2), 48-53.

[40] Strauss, M. J. (1994) A constructivist dialogue, Journal of Humanistic Education and Development, 32 (4), 183 - 187.

[41] Schmitt, B. H. (2003). Customer experience management: A revolutionary approach to connecting with your customers. Hoboken, NJ: John Wiley \& Sons.

[42] Thenell, J. (2004). The library's crisis communications planner: A PR guide for handling every emergency. Chicago: American Library Association.

[43] Vygotsky, L. S. (1962) Thought and Language, Cambridge, MA: MIT Press.

[44] Vygotsky, L. S. (1978) Mind in Society, Cambridge, MA: Harvard University Press. 
[45] Wagner, J. (1994) Learning from a distance, The International Journal of Multimedia, 19 (2): $12-20$

[46] Walter, S. (in press). Moving beyond collections: Academic library outreach to multicultural student centers. Reference Services, Review, 33 (4).

[47] Weiner, S. A. (in press). Library quality and impact: Is there a relationship between new measures and traditional measures? The Journal of Academic Librarianship.DOI: 10.1016/j.acalib.2005.05.004

[48] Weldon, S. (2005). Collaboration and marketing ensure public and medical library viability. Library Trends, 53 (3), 411-421.

[49] Williams, R., Bunn, J., Moore, R.,\&Pool, J.C.T. (1998).Workshop on interfaces to scientific data archives [Online] Pasadena, CA: California Institute of Technology, Center for Advanced Computing Research.
Retrieved May 10, 1999, from the World Wide Web: http://www.cacr.caltech.edu/isda.

\section{AUTHORS PROFILE}

The author is 34 years old and has 6 years of MBA level teaching experience and has presented 5 Research Papers in International Conferences, and have 5 accepted papers for publication in International Journals. The author also has six years of working experience in Banking and Finance, predominantly in Multi-Site, transnational operations encompassing Operations Management and Investment banking. The author is a keen planner, strategist \& implementer with skills in handling complete responsibility for management of departmental administration, organization of study tours, Sports, NSS activities, organizing Medical Camps, training and spearheading campus connect meetings. 